\title{
Effect of Strategic Thinking Skills on Dimensions of Competitive Advantage: Empirical Evidence from Jordan
}

\author{
Ahmed A. Al-Qatamin ${ }^{1}$ \& Ayat Mohammad Esam ${ }^{2}$ \\ ${ }^{1}$ Faculty of Business Studies, Arab Open University, Jordan \\ ${ }^{2}$ Faculty of Business and Finance, World Islamic Sciences and Education University, Jordan \\ Correspondence: Ayat Mohammad Esam, Faculty of Business and Finance, World Islamic Sciences and \\ Education University, Jordan. E-mail: ayat.mohammad@wise.edu.jo
}

Received: January 14, 2018

doi:10.5539/ijbm.v13n5p127
Accepted: March 17, 2018

Online Published: April 18, 2018

\begin{abstract}
The main aim of this research was to conduct an empirical investigation of the effect of strategic thinking skills on the dimensions of competitive advantage using a sample from banking sector in Jordan.

Strategic Thinking Questionnaire (STQ) was used to collect data for the investigation. Four models to capture the effect of each skill of strategic thinking on each dimensions of competitive advantage were developed and tested through several hypotheses using multiple regression analysis as a tool for data analysis and hypotheses testing.

Results indicated that, reflecting as a strategic thinking skill has a significant effect on all dimensions of competitive advantage in all models. On the other hand, the remaining two (system thinking and reframing) skills of strategic thinking failed to show any significant effect on competitive advantage in all models tested in this research.
\end{abstract}

Keywords: strategic thinking, competitive advantage, STQ, strategic management

\section{Introduction}

In our modern time, all business organizations face complex problems due to massive changes taking place in the external environments. These changes require new innovative thinking approaches in order to be able to respond effectively to them. In many cases effective solutions to problems conducted by corporate executives provide only temporary solutions to diversified organizational problems which lead later to the creation of more complex problems. One of these problems is related to difficulties in the process of strategic planning due to the lack of the required strategic thinking on part of the strategic executives.

It has been noted by many researchers that, skills of strategic thinking usually create a dynamic situation at both organizational as well as individual levels. This normally leads to formation of core requirements for the achievement of corporate competitive advantage (Walters, Frome, \& Hend, 2013).

Strategic thinking provides executives with the ability to develop a clearly focused vision and therefore allow them to think with strategic purpose. Having such skills, executives can clearly formulate their organization's strategic objectives and designing strategic action plans to achieve them. An executive with strategic thinking skills can utilize thinking process with high degree of flexibility. Therefore, the most significant trait of strategic thinking can be seen in the ability of managers to employ these advanced human thinking skills in organizational problem solving process and adaptation with external turbulent environment in an innovative manner. This will actually lead to alleviating organizational competitive approaches to the highest possible positions in the competitive markets. Based on this argument, adapting and developing strategic thinking skills should clearly accomplish many advantages to corporations (McCauley, 2012).

\section{Theoretical Background}

Pisapia (2006) indicated that leaders usually fail when facing chaotic, complex and turbulent environments. This usually happened because managers were trained to use their minds according to linear systemic thinking where such mind cannot function properly in all situation.

Due to such work environment they stand helpless to identify critical environmental forces which renders there 
organization unfunctional. This leads to a situation where internal corporate strengths cannot be allied with the required critical path of success.

These findings have been supported by other research findings (Moldoveanu, 2009) which showed that linear thinking does not align with current stage of human history where massive changes are taking place. The conclusion that can be drawn here is that, our modern external environment requires new class of strategic executives with high levels of cognitive and analytical skills.

Golden (2011) defined strategic thinking as a process aims at improving organizational functioning through smart decision making process. Strategic thinking as a concept is usually relayed to innovative approaches. This process requires managerial thought beyond day to day operational thinking that go in line with organization's strategic objectives. Strategic thinking is usually comprised of several activities such as data corrections, an analysis and exchange of thoughts about an issue and a structured way that leads to acquiring correct answers to specific issues.

Strategic thinking is a process that embedded the manner in which people think and rethink, evaluate, view, and conduct the future for themselves and others. Strategic thinking is an extremely effective and valuable tool. One can apply strategic thinking to arrive at decisions that can be related to work or personal life. Strategic thinking involves developing an entire set of critical cognitive and analytical skills.

Executive with Strategic thinking skills have the ability to use the left (logical) and right (creative) sides of their brain, a skill that can be significantly valuable for strategy making process.

Moreover, executives with strategic thinking skills usually have the ability to formulate a clearly focused strategic vision. They have sharp skills at both thinking with a strategic purpose as well as formulating a visioning process. They enjoy both skills and they utilize them in an integrative approach.

Executives with strategic thinking skills have the ability to define their objectives in a focused way and initiate action plan with exact resources to produce high quality output.

Executives with strategic thinking skills usually have the capability to inject strategic flexibility into their strategy by creating benchmarking system for the evaluation and control process. (rbradford@cssp.com)

Strategic thinking is considered a vital business process due to its role in strengthening the overall organizational performance management and effectiveness. Moreover, its connection to new product development is widely considered as a crucial operation for industrial concern.

Based on such rationality, a study was conducted by Syeda Asiya Zenab Kazmi et al (2016) as an attempt to link the concept of strategic thinking with product strategy with the aim of formulating an analytical approach to this relationship. Researchers aimed at formulating a research framework to offer industrial executives, an approach to connect various aspects of this process to corporate strategy and product innovations. A survey was developed and conducted on 30 team members working in the area new product development departments at three locations of a European multinational company. Findings supported the researchers' theoretical hypotheses connecting strategic thinking and new product innovation. The study results indicated that, the most significant variables that have shown positive relationship were early client involvement, customer value, and management initiatives.

Ranjith (2016) conducted a study on the relationship between business models and competitive advantage. His basic theoretical assumption was that firms in the emerging markets main focus are to gain sustainable competitive advantage. The researcher hypothesized that a strong relationship between business models and the competitive advantage does exist. He defined an effective business model as a combination of deliberately manipulated resources and capabilities to create and sustain competitive advantage. The main objective of his research was to conduct an attempt to study the emerging markets business models contribution to competitive advantage. To achieve this end, the researcher has employed multiple case studies which were developed in different time periods. Findings indicated that, companies with multiple business models tended to have higher chances of creating competitive advantage.

Nurul Nadia Abd Aziz and Sarminah Samad (2016), have conducted a study to examine the effect of innovation on competitive advantage in food manufacturing SMEs in Malaysia. Researchers have also investigated the possible moderating effect of firm age on innovation that contributes to the creation of competitive advantage. A random sampling was drawn from the small and medium size Malaysian food manufacturing sector. Subsequently, a structured questionnaire was used to collect data from the selected sample. Suitable descriptive and inferential statistics were utilized to test the study hypotheses. Results of testing the study hypotheses showed that innovation has a strong positive effect on the competitive advantage. Findings confirmed that 
innovation was responsible for 73.5 percent of the variance in competitive advantage, which obviously indicate that for SMEs to gain competitive advantage they must invest heavily in innovation. Another important result was that there was a significant moderating effect of firm age on innovation accounting for competitive advantage.

In an important multi- cultural study conducted by Pisapia et al (2009), Cognition was viewed as the way human uses mental processing to acquire knowledge, manipulate ideas, and process information and beliefs. The Strategic Thinking Questionnaire (STQ), which measures three such mental process (systems thinking, reframing and reflection), was used in this research to collect data from samples of students who are preparing for school leadership roles at four universities in the United States, Malaysia, Hong Kong, and Shanghai in China. Researchers were operating under the assumption that the use of these skills should vary from country to country due to western and eastern varying cultural settings. To the researcher surprise, and based on self-reported data from 328 respondents, researchers found that the use of strategic thinking skills (system thinking, reframing and reflecting) were observed in all locations but the variance in their use is more a function of age of respondents, and gender rather than location. Based on these findings, the researchers asserted that these findings have significant implications for training, professional development, and selection of strategic leaders.

The theme of the previous argument should lead to the conclusion that, to think strategically as previous literature implies, strategists have to develop a full understanding of the processes of strategic thinking and its connections to contextual environments in which the strategic thinking is taking place. Under such consideration, the nature of the competitive landscape usually set the requirements for thinking strategically, and as the environment become more complex, additional considerations had to be integrated into the strategic thinking system.

\section{Objective of the Research}

This research aims at the assessment of the effect of strategic thinking on the achievement of competitive advantage on a sample of banking firms in Jordan.

\section{Research Methodology}

To reach the above objective, researchers have designed the following model for this investigation.

\subsection{The Independent Variables:}

For the purpose of this research strategic thinking is going to represent the independent variable which is comprised of three dimensions called skills of strategic thinking.

\subsubsection{Dimension One: Reflecting}

Reflecting refers to the ability of a leader to integrate logical and rational thinking processes together using experience, perception and information to make sound judgement about certain state of affair then initiate a concept that guides what would happen at present and help guide the future perspective (Pisapia, 2009).

\subsubsection{Dimension Two: Reframing}

Reframing refers to the ability of an executive to cover wide range of perspectives, switching flexibly across multiple strategic modes and mental models. This trait is vital for strategic leaders to help them generate strategic options and focus on the essentials. It enables executives to classify opportunities and strategic options so that focus continues to be sharp on vital component of strategic issues. It also helps them to see threats and problems in a clear manner allowing them to map out options and identify trends ahead of other competitors, (Pisapia, 2009).

\subsubsection{Dimension Three: System Thinking}

System thinking refers to the ability of an executive to observe systems comprehensively and interactively by understanding the inner function ability and interrelationships that interact to create patterns of behaviors which help generate sound strategic options. It is that holistic capable mind which can be able to define the entire situation and breaking it downs into manageable parts to facilitate identifying suitable solutions, (Pisapia, 2009).

\subsection{The Dependent Variable}

For the purpose of this research competitive advantage is going to represent the dependent variable. Four dimensions of competitive advantage are going to be used here. 


\subsubsection{Dimension of Cost}

This dimension represents the firm ability to reduce total cost of operations thus increasing profitability compared to competitors. It includes measures reducing production cost and minimization of waste and bad products. Some of the most important features of cost may refer to having standardized products, reasonable quality and product features, putting more emphasis on production efficiency, and conducting continuous cost reduction in the area of value chain activities.

It may also include considerations related to the management of manufacturing cost, value added, running cost and service cost.

\subsubsection{Dimension of Quality}

This dimension represents the firm ability to present the market with unique product that differentiates it from competitors. It includes measures such as managing quality and quality assurance, systems of quality feedback, and level of employees' qualifications. This dimension may include performance and features of products, reliability and conformance of products to specifications, durability and serviceability, value to customer and reputation.

\subsubsection{Dimension of Flexibility}

This dimension involves firm's ability to produce and successfully market new products and make modifications to old products.

It may include several activities such as ability to successfully manage incoming materials of different quality, and ability to satisfy demand for different levels of quality, and ability to manage the introduction of new products to markets.

Flexibility as dimension of competitive advantage can also be seen in activities such as the company capability to modifying existing products to respond to customer changes in preferences and needs, ability to cope with changes in the product mix in changes in resource mix.

\subsubsection{Dimension of Time and Delivery}

This dimension represents firm's ability to provide on time services in an integrative manner. This process may include delivery component such as manufacturing lead time, levels of due date activities, Rate of product introduction, Delivery lead time and frequency of delivery.

\subsection{The Research Tool}

In an attempt to present an evidence of the significance of strategic thinking skills as related to competitive advantage, the researchers have conducted a thorough survey of the previous literature to build up a suitable theoretical background. Then a questionnaire was borrowed from Pisapia (2007) to measure strategic thinking, and used to collect primary data from the whole population of 16 banks operating in the banking industry in Jordan. The targeted unit of the sample was the executives at different managerial levels in these banks. In this study, the target population was approximately 227 executive managers.

This questionnaire has been developed by Pisapia and subjected to several validations over several years and proved to be valid and reliable. It has been also translated into several languages and used in subsequent research by many researchers.

It has been designed to provide an empirical assessment of three strategic thinking skills: reflecting, reframing and system thinking. It is believed that these three cognitive strategic thinking skills should represents respondents' ability to think in a flexible and strategic manner, thus provide them with necessary skills to lead strategically.

"The original STQ developers Pisapia, Reyes-Guerra, and Coukos (2005) have reviewed the literature and then defined the three cognitive skills. Using the definitions as guides, they wrote statements describing skills required to think in systems, reframing, and reflection terms. A panel of five experts knowledgeable about strategic thinking reviewed the resulting 180 items. They sorted the statements into the three categories. In an iterative fashion, the statements were modified or discarded following lengthy discussions and repeated feedback sessions between the panel and researchers. Items on the STQ are cast on a five-point Likert scale. A higher value represents greater use of a cognitive skill, as noted below "as follows:"

\section{$1=$ Almost Never uses}

$2=$ Rarely uses 
$3=$ Sometimes uses

$4=$ Frequently uses

5= Almost Always uses

For the purpose of collecting primary data for dimensions of competitive advantage, a questionnaire was borrowed from Nsour (2016) and used to collect data for this purpose.

In this questionnaire based on the operational definitions developed, the dimensions of competitive advantage was measured through 22 statements on a Likert five-scale system ranging from very low to very high. The cost dimension of competitive advantage was represented by 6 statements from 1-6, followed by the quality dimension represented by 6 statements from 7-12. The dimension of flexibility was represented by 7 statements from 13-19. Lastly, the delivery dimension of the competitive advantage was measured by 3 statements from $19-22$.

Both questionnaires were reproduced and distributed to all banks in Jordan. A total of 100 usable questionnaires was received and used in this research.

\section{Analysis of Demographics of Respondents}

Following is the main demographic characteristics of the respondents who have been selected to participate as a sample in this research.

A total of 100 respondents were filled out the survey and researchers included them in the analysis.

Distribution of the study sample according to gender indicated that 61 (61.6 percent) males and 38 (38.4 percent) females as shown in Table 1, where 15.2 percent of them classified in the strategic level, 39.4 percent in the functional level, and 55.5 are in the operational management level as reported in table (2).

Table 1. Gender

\begin{tabular}{lcccc}
\hline & Frequency & Percent & Valid Percent & Cumulative Percent \\
\hline $\mathrm{M}$ & 61 & 61.6 & 61.6 & 61.6 \\
$\mathrm{~F}$ & 38 & 38.4 & 38.4 & 100.0 \\
Total & 99 & 100.0 & 100.0 & \\
\hline
\end{tabular}

Table 2. Managerial Level

\begin{tabular}{lcccc}
\hline & Frequency & Percent & Valid Percent & Cumulative Percent \\
\hline Strategic & 15 & 15.2 & 15.2 & 15.2 \\
Functional & 39 & 39.4 & 39.4 & 54.5 \\
Operational & 45 & 45.5 & 45.5 & 100.0 \\
Total & 99 & 100.0 & 100.0 & \\
\hline
\end{tabular}

Table 3 shows the distribution of the study sample according to years of experience in the company. As shown, 18 (18.2 percent) of the respondents have 1-3 years' experience, 30 (30.3 percent) have 3-5 years' experience and finally 51 (51.1 percent) have more than five years' experience.

Table 3. Experience

\begin{tabular}{lcccc}
\hline & Frequency & Percent & Valid Percent & Cumulative Percent \\
\hline 1-3 Years & 18 & 18.2 & 18.2 & 18.2 \\
3-5 years & 30 & 30.3 & 30.3 & 48.5 \\
more than 5 & 51 & 51.5 & 51.5 & 100.0 \\
Total & 99 & 100.0 & 100.0 & \\
\hline
\end{tabular}

\section{Models Formulated and Tested}

For the purpose of this research and based in the previous theoretical background developed earlier, the following four models were formulated and tested using Multiple regression analysis as a statistical technique for data analysis. 
This categorization of the research design generates four regression models:

\subsection{First Model}

$$
Y 1=a+b 1 x 1+b 2 \times 2+b 3 \times 3
$$

Where,

$\mathrm{Y} 1$ is the cost dimension of the competitive advantage

$\mathrm{a}$ is the intercept,

$\mathrm{b} 1$ is the regression coefficient of $\mathrm{x} 1$,

$\mathrm{b} 2$ is the regression coefficient of $\mathrm{x} 2$ and,

$\mathrm{b} 3$ is the regression coefficient of $\mathrm{x} 3$.

$\mathrm{X} 1$ is the reflection dimension of strategic thinking

$\mathrm{X} 2$ is the reframing dimension of strategic thinking

$\mathrm{X} 3$ is the system thinking of strategic thinking

6.2 Second Model

$$
\mathrm{Y} 2=\mathrm{a}+\mathrm{b} 1 \mathrm{x} 1+\mathrm{b} 2 \times 2+\mathrm{b} 3 \times 3
$$

Where,

$\mathrm{Y} 2$ is the quality dimension of competitive advantage, and other parameters and independent variables are as in model one.

\subsection{Third Model}

$$
Y 3=a+b 1 x 1+b 2 \times 2+b 3 \times 3
$$

Where $\mathrm{Y} 3$ is the flexibility dimension of competitive advantage and other parameters and independent variables are as in model one.

\subsection{Fourth Model}

$$
\mathrm{Y} 4=\mathrm{a}+\mathrm{b} 1 \times 1+\mathrm{b} 2 \times 2+\mathrm{b} 3 \times 3
$$

Where $\mathrm{Y} 4$ is the time and delivery dimension of competitive advantage and other parameters and independent variables are as in model one.

\section{The Research Hypotheses}

To reach the intended outcome of this research, following are the hypotheses developed by the researchers and stated in a null format:

H01: Strategic thinking skills (reflecting, reframing and system thinking) have significant effect on the cost dimension of competitive advantage.

H02: Strategic thinking skills (reflecting, reframing and system thinking) has significant effect on the quality dimension of competitive advantage

H03: Strategic thinking skills (reflecting, reframing and system thinking) has significant effect on the flexibility dimension of competitive advantage

H04: Strategic thinking skills (reflecting, reframing and system thinking) have significant effect on the delivery dimension of competitive advantage.

This impact of the independent variables on the dependent variables in these models is going to be considered significant at $(0.05)$ or less.

\section{Results of Testing the Research Hypotheses}

Following are the results of testing the research hypotheses after applying multiple regression analysis:

Model one:

$$
\mathrm{Y} 1=\mathrm{a}+\mathrm{b} 1 \mathrm{x} 1+\mathrm{b} 2 \mathrm{x} 2+\mathrm{b} 3 \times 3+\mathrm{b} 4 \mathrm{x} 4
$$

Y1 (Dependent variable) is cost dimension of competitive advantage

Table 4 shows the results of testing the goodness of fit of model one. Results indicated that the f-statistics is 2.666 and the related significance is 0.05 . Based on these values the model is fit for testing the hypotheses. 
Table 4. Result of testing model one goodness of fit

\begin{tabular}{|c|c|c|c|c|c|}
\hline Model & Sum of Squares & df & Mean Square & $\mathrm{F}$ & Sig. \\
\hline Regression & 2.837 & 3 & .946 & 2.666 & $.052 \mathrm{a}$ \\
\hline Residual & 33.702 & 95 & .355 & & \\
\hline
\end{tabular}

a. Predictors: (Constant), System Thinking, reframing, Reflecting

b. b. Dependent Variable: Cost Dimension

Table 5 shows the parameters related to testing hypotheses in this model. As indicated, both reflecting and system thinking has no significant effect on the cost dimension of competitive advantage, therefore both null hypotheses are accepted. On the other hand, reframing has a moderate significant effect $(\mathrm{p}=0.07)$, which permits researchers to reject the null hypothesis and conclude that reframing as a skill of strategic thinking may influence the cost dimension of competitive advantage moderately.

Table 5. Results of testing hypotheses for model one

\begin{tabular}{|c|c|c|c|c|c|c|}
\hline \multirow[t]{2}{*}{ Model } & & \multicolumn{2}{|c|}{$\begin{array}{l}\text { Unstandardized } \\
\text { Coefficients }\end{array}$} & \multirow{2}{*}{$\begin{array}{l}\text { Standardized Coefficients } \\
\text { Beta } \\
\end{array}$} & \multirow[t]{2}{*}{$\mathrm{t}$} & \multirow[t]{2}{*}{ Sig. } \\
\hline & & $\mathrm{B}$ & Std. Error & & & \\
\hline & (Constant) & 2.378 & .553 & & 4.299 & .000 \\
\hline & Reframing & .212 & .118 & .187 & 1.800 & .075 \\
\hline & Reflecting & .143 & .163 & .127 & .877 & .383 \\
\hline & SystemThinking & .045 & .176 & .036 & .256 & .799 \\
\hline
\end{tabular}

a. Dependent Variable: Cost Dimension
Model two:
$\mathrm{Y} 2=\mathrm{a}+\mathrm{b} 1 \times 1+\mathrm{b} 2 \times 2+\mathrm{b} 3 \times 3$

Y2 (dependent variable) is the quality dimension of competitive advantage. Results of testing the goodness of fit for this model are shown in Table (6) below. Since f-stat is 4.531 and its significance is 0.005 , researchers concluded that the goodness of fit of this model is significant and therefore model is fit for testing the hypotheses.

Table 6. Results of testing model two for goodness of fit

\begin{tabular}{llllll}
\hline Model & Sum of Squares & df & Mean Square & F & Sig. \\
\hline Regression & 6.238 & 3 & 2.079 & .531 & $.005 \mathrm{a}$ \\
Residual & 43.598 & 95 & .459 & \\
Total & 49.836 & 98 & & \\
\hline
\end{tabular}

a. Predictors: (Constant), System Thinking, reframing, Reflecting

b. Dependent Variable: Quality Dimension

Table 7 shows the results of testing the hypotheses in this model. As shown, reflecting has highly significant effect $(\mathrm{p}=0.004)$ and system thinking has a moderate effect on the quality dimension of competitive advantage. On the other hand no significant effect of reframing was detected. 
Table 7. Results of testing the hypotheses for model two dependent variable: quality dimension

\begin{tabular}{|c|c|c|c|c|c|}
\hline \multirow[t]{2}{*}{ Model } & \multicolumn{2}{|c|}{$\begin{array}{l}\text { Unstandardized } \\
\text { Coefficients }\end{array}$} & \multirow{2}{*}{$\begin{array}{l}\text { Standardized Coefficients } \\
\text { Beta }\end{array}$} & \multirow[t]{2}{*}{$\mathrm{t}$} & \multirow[t]{2}{*}{ Sig. } \\
\hline & $\mathrm{B}$ & Std. Error & & & \\
\hline (Constant) & 2.453 & .629 & & 3.898 & .000 \\
\hline Reframing & .194 & .134 & .147 & 1.450 & .150 \\
\hline Reflecting & .540 & .185 & .410 & 2.916 & .004 \\
\hline System & -.350 & .200 & -.241 & -1.746 & .084 \\
\hline Thinking & & & & & \\
\hline
\end{tabular}

Model three:

$\mathrm{Y} 3=\mathrm{a}+\mathrm{b} 1 \mathrm{x} 1+\mathrm{b} 2 \times 2+\mathrm{b} 3 \times 3$

Y3 (dependent variable) is the flexibility dimension of competitive advantage.

As shown in Table 8, model three has highly significant goodness of fit since f-stat is 5.754 and its significance is 0.001 which indicate that the model is fit for testing the hypotheses.

Table 8. Results of testing model three goodness of fit

\begin{tabular}{lllllll}
\hline Model & & Sum of Squares & Df & Mean Square & F & Sig. \\
\hline & Regression & 5.210 & 3 & 1.737 & 5.754 & $.001 \mathrm{a}$ \\
& Residual & 28.673 & 95 & .302 & & \\
& Total & 33.883 & 98 & & & \\
\hline
\end{tabular}

a. Predictors: (Constant), System Thinking, reframing, Reflecting

b. Dependent Variable: Flexibility Dimension

Results of testing the model hypotheses are shown in Table 9. As indicated, both null hypotheses for reframing and system thinking were accepted, indicating that they have no significant effect on the flexibility dimension of competitive advantage.

On the other hand, the null hypothesis is rejected at $(\mathrm{p}=0.033)$, concluding that reflecting has significant effect on the flexibility dimension of competitive advantage.

Table 9. Results of testing the hypotheses for model three

\begin{tabular}{|c|c|c|c|c|c|}
\hline \multirow[t]{2}{*}{ Model } & \multicolumn{2}{|c|}{ Unstandardized Coefficients } & \multirow{2}{*}{$\begin{array}{l}\text { Standardized } \\
\text { Coefficients } \\
\text { Beta }\end{array}$} & \multirow[t]{2}{*}{$\mathrm{t}$} & \multirow[t]{2}{*}{ Sig. } \\
\hline & $\mathrm{B}$ & Std. Error & & & \\
\hline (Constant) & 2.079 & .510 & & 4.074 & .000 \\
\hline Reframing & .110 & .109 & .101 & 1.009 & .315 \\
\hline Reflecting & .326 & .150 & .300 & 2.168 & .033 \\
\hline System Thinking & .076 & .162 & .063 & .466 & .642 \\
\hline
\end{tabular}

a. Dependent Variable: Flexibility Dimension

Model four: $\quad \mathrm{Y} 4=\mathrm{a}+\mathrm{b} 1 \times 1+\mathrm{b} 2 \times 2+\mathrm{b} 3 \times 3+\mathrm{b} 4 \times 4$

Y4 (dependent variable) is the delivery dimension of competitive advantage.

Table 10 shows the results of testing model four's goodness of fit. As indicated, the model is fit since f-stat is 2.836 and its significance is 0.042 . Therefore the model is fit for hypotheses testing. 
Table 10. Results of testing model four goodness of fit

\begin{tabular}{clllll}
\hline Model & Sum of Squares & df & Mean Square & F & Sig. \\
\hline Regression & 6.970 & 3 & 2.323 & .836 & \\
Residual & 77.827 & 95 & .819 & & \\
Total & 84.797 & 98 & & & \\
\hline
\end{tabular}

a. Predictors: (Constant), System Thinking, reframing, Reflecting

b. Dependent Variable: Delivery Dimension

Table 11 shows the Statistic parameters for testing these model hypotheses. As shown, null hypotheses related to reframing and system thinking were accepted, indicating that both strategic thinking skills do not have any significant effect on the delivery dimension of competitive advantage.

On the other hand, null hypothesis related to the effect of reflecting was rejected concluding that reflecting as a strategic thinking skill has significant effect on the delivery dimension of competitive advantage.

Table 11. Results of testing the hypotheses for model four

\begin{tabular}{|c|c|c|c|c|c|}
\hline \multirow[t]{2}{*}{ Model } & \multicolumn{2}{|c|}{ Unstandardized Coefficients } & \multirow{2}{*}{$\begin{array}{l}\text { Standardized } \\
\text { Coefficients } \\
\text { Beta }\end{array}$} & \multirow[t]{2}{*}{$\mathrm{t}$} & \multirow[t]{2}{*}{ Sig. } \\
\hline & $\mathrm{B}$ & Std. Error & & & \\
\hline (Constant) & 1.973 & .841 & & 2.347 & .021 \\
\hline Reframing & .199 & .179 & .115 & 1.111 & .270 \\
\hline Reflecting & .490 & .248 & .285 & 1.981 & .051 \\
\hline System Thinking & -.164 & .268 & -.087 & -.612 & .542 \\
\hline
\end{tabular}

a. Dependent Variable: Delivery Dimension

\section{Conclusions and Discussions}

As presented in the previous section, results of testing the research hypotheses yielded the following conclusions:

1- The constant was always significant in all models indicating that there are other independent variables other than those included in the model which have significant effect on competitive advantage in the four dimensions used in this research.

2- Reflecting as a skill of strategic thinking has always been significant in all models except in model one (cost dimension) indicating that it has the most effect on all dimensions of competitive advantage. The values of $\mathrm{t}$ and alpha were 2.916 at 0.004 for quality for flexibility, 2.168 at .03, and 1.981 at 0.05 level of significance for delivery dimension.

3- Reframing as a skill in strategic thinking has a slightly positive non-significant effect on the dimensions of competitive advantage in all models.

4- System thinking as a skill in strategic thinking has a very week negative non-significant effect on the dimensions of competitive advantage in all models.

These results allows researchers to conclude that, in this sample only reflecting as a skill in the process of strategic thinking has a constant and significant effect on all dimensions of competitive advantage except the cost dimension.

This results might have been materialized because of the fact that Reflecting refers to the ability of a leader to integrate logical and rational thinking processes together using experience, perception and information to make sound judgement about certain state of affair then initiate a concept that guides what would happen at present and help guide the future perspective.

Such skill seems to be the most important strategic thinking skill due to its close relation to decision making. In the final analysis, decision making capability of a strategic leader is so vital for the leader to deal with current as well as future complex circumstances.

Finally future research on this topic should be extended to include other sectors of the Jordanian economy such as industrial sector so that a better understanding of the relationships embedded in this study results can be 
realized.

One limitation of the research is that it is restricted to one country and a sample from one industry namely the banking sector in Jordan which led to a small sample size. The cross sectional nature of the research may also be considered as one more limitation for the current research.

\section{References}

Casey, A. J., \& Goldman, E. F. (2010). Enhancing the ability to think strategically: A learning model. Management Learning, 41(2), 167-185. https://doi.org/10.1177/1350507609355497

Goldman, E. (2016). Strategic Thinking at the Top. MIT Sloan Management Review, 26(4).

Goldman, E. F., \& Casey, A. J. (2010). Building a culture that encourages strategic thinking. Journal of Leadership \& Organizational Studies, 17(2), 119-128. https://doi.org/10.1177/1548051810369677

McCauley, D. (2012). Strategic thinking: Providing the competitive edge. Small Wars Journal, 8(2). Retrieved from http://smallwarsjournal.com/jrnl/art/strategic-thinking-providingthe-competitive-edge

Moldoveanu, M. (2009). Thinking strategically about thinking strategically: The computational structure and dynamics of managerial problem selection and formulation. Strategic Management Journal, 30(7), 737-763. https://doi.org/10.1002/smj.757

Nurul, N. A. A., \& Sarminah, S. (2016). Innovation and Competitive Advantage: Moderating effects of Firm Age in Foods Manufacturing SMEs in Malaysia. Procedia Economics and Finance, 35, 256-266.

Pisapia et al. (2009). A Comparison of the Use of Strategic Thinking Skills of Aspiring School Leaders in Hong Kong, Malaysia, Shanghai, and the United States: An Exploratory Study. International Education Studies, 2(2).

Ranjith, R. J. (2015). Business Models and Competitive Advantage. Procedia Economics and Finance, 37, 203-207. F

Syeda, A. Z. K. et al. (2016). Procedia - Social and Behavioral Sciences. Connecting strategic thinking with product innovativeness to reinforce NPD support process. 12th International Strategic Management Conference, Antalya, Turkey

Waters, D. E. (2011). Understanding Strategic Thinking and Developing Strategic Thinkers. Joint Forces Quarterly, 63, 113-119.

Wolters, H. M. K., Grome, A. P., \& Hinds, R. M. (Eds.) (2013). Exploring strategic thinking: Insights to assess, develop, and retain Army strategic thinkers (Research Product 20131). Fort Belvoir, VA: U.S. Army Research Institute for the Behavioral and Social Sciences. ADA57729.

\section{Copyrights}

Copyright for this article is retained by the author(s), with first publication rights granted to the journal.

This is an open-access article distributed under the terms and conditions of the Creative Commons Attribution license (http://creativecommons.org/licenses/by/4.0/). 